ARTICLE

\title{
Near $100 \%$ ethene selectivity achieved by tailoring dual active sites to isolate dehydrogenation and oxidation
}

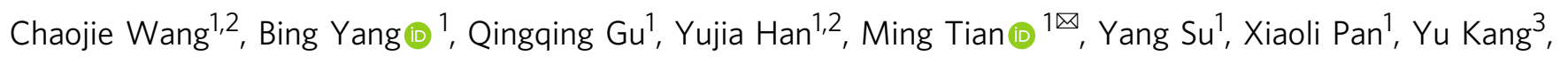
Chuande Huang ${ }^{1}$, Hua Liu ${ }^{1,2}$, Xiaoyan Liu (1) ${ }^{1}$, Lin Li $^{1} \&$ Xiaodong Wang (1) ${ }^{1 \times}$

Prohibiting deep oxidation remains a challenging task in oxidative dehydrogenation of light alkane since the targeted alkene is more reactive than parent substrate. Here we tailor dual active sites to isolate dehydrogenation and oxidation instead of homogeneously active sites responsible for these two steps leading to consecutive oxidation of alkene. The introduction of $\mathrm{HY}$ zeolite with acid sites, three-dimensional pore structure and supercages gives rise to $\mathrm{Ni}^{2+}$ Lewis acid sites (LAS) and $\mathrm{NiO}$ nanoclusters confined in framework wherein catalytic dehydrogenation of ethane occurs on $\mathrm{Ni}^{2+}$ LAS resulting in the formation of ethene and hydrogen while $\mathrm{NiO}$ nanoclusters with decreased oxygen reactivity are responsible for selective oxidation of hydrogen rather than over-oxidizing ethene. Such tailored strategy achieves near $100 \%$ ethene selectivity and constitutes a promising basis for highly selective oxidation catalysis beyond oxidative dehydrogenation of light alkane.

\footnotetext{
${ }^{1}$ CAS Key Laboratory of Science and Technology on Applied Catalysis, Dalian Institute of Chemical Physics, Chinese Academy of Sciences, Dalian, People's Republic of China. ${ }^{2}$ University of Chinese Academy of Sciences, Beijing, People's Republic of China. ${ }^{3}$ Max Planck Institute for Chemical Physics of Solids,

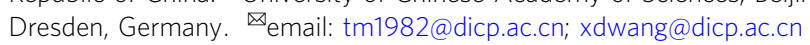


$\mathrm{O}$ xidation catalysis plays a pivotal role in establishing green and sustainable chemical applications and contributes approximately $30 \%$ of total production in the chemical industry, such as selective oxidation of methanol to formaldehyde, propene to acrolein, butane to maleic anhydride, and ethene to ethylene epoxide, as well as the production of key pharmaceutical intermediates ${ }^{1}$. Unfortunately, a general and long-standing scientific conundrum is over-oxidation of desired product which is more reactive than parent substrate, impeding the industrialization process of numerous oxidation reactions with game-changing industrial value and economic benefits. Hence, selectively oxidative heterogeneous catalysis to restrain over-oxidation is significant but challenging whether for fundamental studies or practical applications ${ }^{2-5}$.

The oxidative dehydrogenation of light alkanes to olefins $(\mathrm{ODH})$ which are important building blocks for a handful of industrial processes is a well-known example of such a challenging reaction that is a promising alternative to the current industrial practice of steam cracking with no thermodynamic limitation, coke formation, and large $\mathrm{CO}_{2}$ emission but difficult to realize commercialized utilization impeded by the liable deep oxidation $^{6-9}$. This was because alkene is facile to be further oxidized before its desorption or re-adsorbed on the active sites of dehydrogenation (usually oxygen species) according to the Mars-van Krevelen mechanism ${ }^{1,10,11}$ which resulted from its higher affinity and reactivity than alkane to most surfaces particularly for those of $\mathrm{V}$ - and Ni-based catalysts which have been studied most for $\mathrm{ODH}^{12-17}$. Extensive studies have contributed to manipulating the chemical environment of active oxygen species to decrease its insertion as large extent as possible concurrently with activation for $\mathrm{C}-\mathrm{H}$ bond in alkane. It was reported that supporting $\mathrm{V}_{2} \mathrm{O}_{5}$ and $\mathrm{NiO}$ with smaller clusters on the inert oxides such as $\mathrm{SiO}_{2}$ and $\mathrm{Al}_{2} \mathrm{O}_{3}$ led to the decrease in the reactivity of active lattice oxygen species to alkene thereby its further oxidation was alleviated, which stemmed from increased metal - oxygen bond strength. However, the activation for alkane declined ${ }^{18-20}$. Multiple metals doped vanadium oxide, e.g. Mo-V $-\mathrm{Te}-\mathrm{Nb}$ mixed oxides were also reported to exhibit high ethene selectivity, which could be attributed to the $\mathrm{V}=\mathrm{O}$ sites or redoxactive $\mathrm{O}^{-}$radical sites generated by the reduction of $\mathrm{Te}^{4+}$ to $\mathrm{Te}^{0}$ with low reactivity to ethene $e^{7,8,21}$. Recently, hexagonal boron nitride $(\mathrm{BN})$ attracted continuous interest thanks to its unexpected olefin selectivity, which originated from the stabilization of propyl species by the nitroxyl radical in the active sites of $>\mathrm{B}-\mathrm{O}$ $-\mathrm{O}-\mathrm{N}<$ rather than highly reactive propyl radicals thus suppressing over-oxidation ${ }^{22,23}$. In addition, decreasing the number and restricting the local availability of active but nonselective such as electrophilic oxygen species $\mathrm{O}^{-}$could also increase alkene selectivity induced by the decrease in the probability of continuous oxidation for various metals with higher valence doped $\mathrm{NiO}$ materials ${ }^{24-29}$. It was further clarified that isolated electrophilic oxygen species played a positive role for high ethene selectivity resulted from its effective breakage of $\mathrm{C}-\mathrm{H}$ bonds of ethane to selectively produce ethylene with easy desorption ${ }^{30,31}$. a
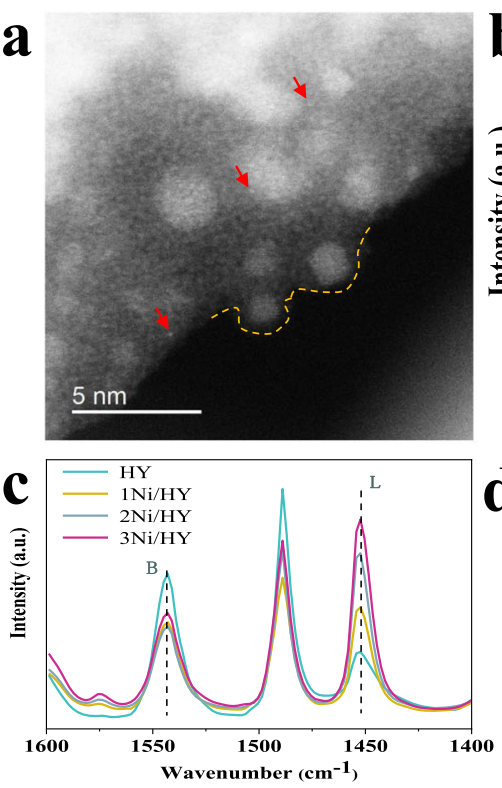

e

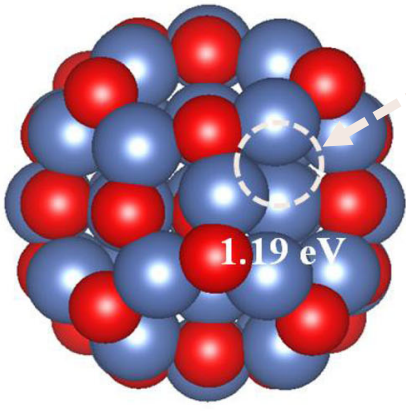

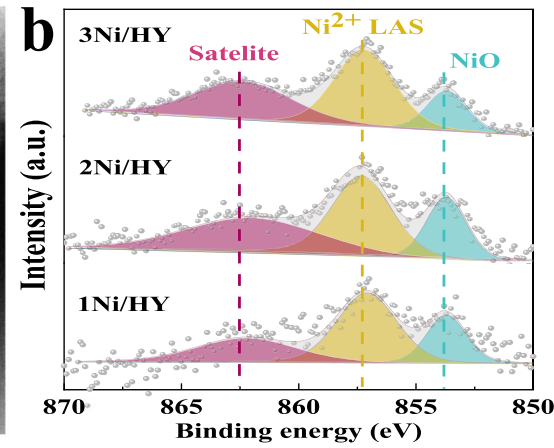

d
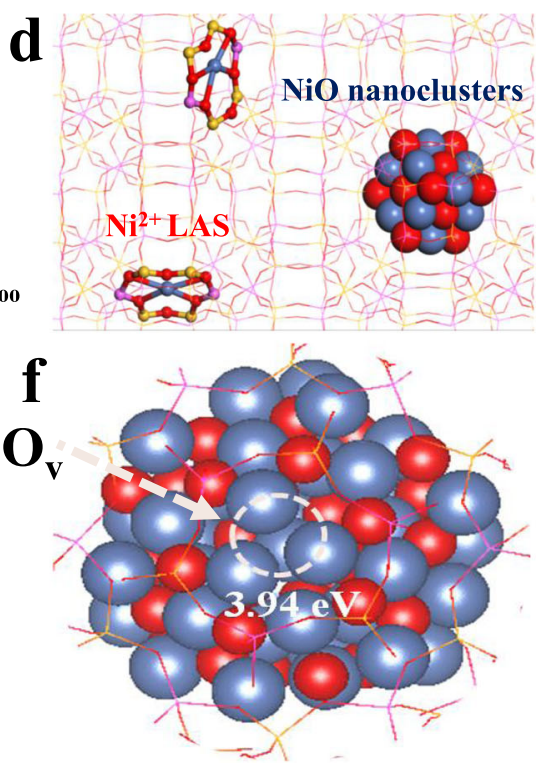

Fig. 1 Characterizations of the $\mathbf{x N i} / \mathbf{H Y}$. a AC-TEM image of 3Ni/HY sample. $\mathbf{b}$ XPS spectra of fresh $x \mathrm{Ni} / \mathrm{HY}$. c Pyridine adsorption FT-IR spectra of $x$ Ni/ $\mathrm{HY}$, where Brønsted (B) and Lewis ( $L$ ) acid sites are observed at around 1540 and $1450 \mathrm{~cm}^{-1}$, respectively. $\mathbf{d}$ Scheme of the proposed local structure of Nimodified HY. DFT calculation models and results of $\mathbf{e} 1 \mathrm{~nm} \mathrm{NiO}$ cluster and $\mathbf{f}$ that confined inside zeolite. (Ov stands for oxygen vacancy). 
Although great effort has been made, over-oxidation remains not to be completely avoided probably due to the difficulty to manipulate identical active sites such as oxygen species responsible for both dehydrogenation and oxidation resulting in facile further oxidation of alkene on it particularly when conversion increases. Consequently, it can be feasible to avert over-oxidation that dehydrogenation and oxidation occur on different active sites.

Herein, strategically tailoring dual $\mathrm{Ni}$ active sites is proposed by utilizing the acid sites, three-dimensional pore structure, and supercages of $\mathrm{HY}$ zeolite to anchor $\mathrm{Ni}^{2+}$ Lewis acid sites (LAS) and confine $\mathrm{NiO}$ clusters to isolate dehydrogenation and oxidation by lattice oxygen, respectively ${ }^{2,32-36}$. As a result, this strategy avoids consecutive oxidation and achieves near $100 \% \mathrm{C}_{2} \mathrm{H}_{4}$ selectivity at a wider range of conversion compared with those reported in the previous work ${ }^{37-40}$. Experiments and theory studies indicate that such tailored dual active sites realizing isolated dehydrogenation and oxidation play a crucial role in avoiding over-oxidation of ethene.

\section{Results}

Catalysts preparation and characterization. The $x \mathrm{Ni} / \mathrm{HY}$ were prepared with succinct and effective wet impregnation to create dual active sites to satisfy the need of isolating dehydrogenation and oxidation. A series of characterization was carried out to verify if $\mathrm{HY}$ introduced gave rise to dual $\mathrm{Ni}$ active sites. Firstly, high-angle annular dark-filed scanning transmission electron microscopy (HAADF-STEM) combined with energy dispersive spectrometer (EDS) mappings showed that $\mathrm{Ni}$ species with the exclusive valence state of +2 proved by $\mathrm{Ni}$ k-edge $\mathrm{X}$-ray absorption near-edge spectrum (XANES) (Supplementary Fig. 2) were highly dispersed and well distributed with $\mathrm{Si}, \mathrm{Al}$ and $\mathrm{O}$ elements with particle size ranging from 0.6 to $1.7 \mathrm{~nm}$ in $x \mathrm{Ni} / \mathrm{HY}$, which indicated that they entered the framework of HY for $x \mathrm{Ni}$ / HY (Supplementary Figs. 1, 3a-c). Aberration-corrected transmission electron microscope (AC-TEM) indicated the presence of two kinds of $\mathrm{Ni}$ species including the isolated cationic $\mathrm{Ni}^{2+}$ and
$\mathrm{NiO}$ nanoclusters confined in $\mathrm{HY}$ framework in $3 \mathrm{Ni} / \mathrm{HY}$ (Fig. 1a and Supplementary Fig. 4). X-ray photoelectron spectroscopy (XPS) presented that a peak at higher binding energy of about $857 \mathrm{eV}$ attributed to isolated $\mathrm{Ni}^{2+}$ cations in $\mathrm{HY}$ with electron transferring to zeolite framework ${ }^{41}$ was also observed besides a peak at around $854 \mathrm{eV}$ ascribed to $\mathrm{NiO}^{42}$ (Fig. 1b). It was reported that the introduction of metal species into zeolites would induce the generation of LAS by the substitution of Brønsted acid sites (BAS) ${ }^{43}$. Thus, the Ni species in the form of cations might be associated with $\mathrm{Ni}^{2}+$ LAS in HY. Pyridine adsorption FTIR spectra was performed to study $\mathrm{Ni}^{2+}$ LAS in HY. Three peaks of 1547, 1490, and $1455 \mathrm{~cm}^{-1}$ were seen (Fig. 1c) for HY, which corresponded to pyridine adsorption on BAS, BAS, and LAS, and LAS $^{44}$. Significant increase of LAS and concurrent decrease of BAS content was observed for $x \mathrm{Ni} / \mathrm{HY}$ and the variation extent becomes more prominent with Ni loadings, which suggested that $\mathrm{Ni}^{2+}$ LAS was generated by the substitution of protons of BAS in HY. This could be further supported by in situ FTIR wherein hydroxyl species associated with BAS in zeolites $\left(3602 \mathrm{~cm}^{-1}\right)$ was remarkably dropped for $x \mathrm{Ni} / \mathrm{HY}$ samples compared with $\mathrm{HY}^{45}$ (Supplementary Fig. 5). UV-vis-NIR spectroscopy was employed to investigate the coordination environment of $\mathrm{Ni}$ cations in $3 \mathrm{Ni} /$ HY. A peak at around $425 \mathrm{~nm}$ attributed to $d-d$ transition band of $\mathrm{NiO}$ had a visible blue shift for $x \mathrm{Ni} / \mathrm{HY}$ in Supplementary Fig. 6, which indicated the decrease of coordination number of confined Ni species in HY compared with 6-coordinated octahedron structure within the $\mathrm{NiO}^{11,41}$. Density functional theory (DFT) calculation was then performed to determine the structure of Ni cations in HY. We compared several different local structures and found that Ni preferred sitting inside a six-member ring with two $\mathrm{Al}$ atoms and was four-coordinated by framework oxygen atoms (Supplementary Fig. 7). Other structures such as Ni sitting in different six-member or larger rings were less stable. Taken together, we successfully fabricated dual $\mathrm{Ni}$ active sites by HY introduced as presented in Fig. 1d, which might isolate dehydrogenation and oxidation thus avoiding over-oxidation. This was different from traditional ODH catalysts in which these
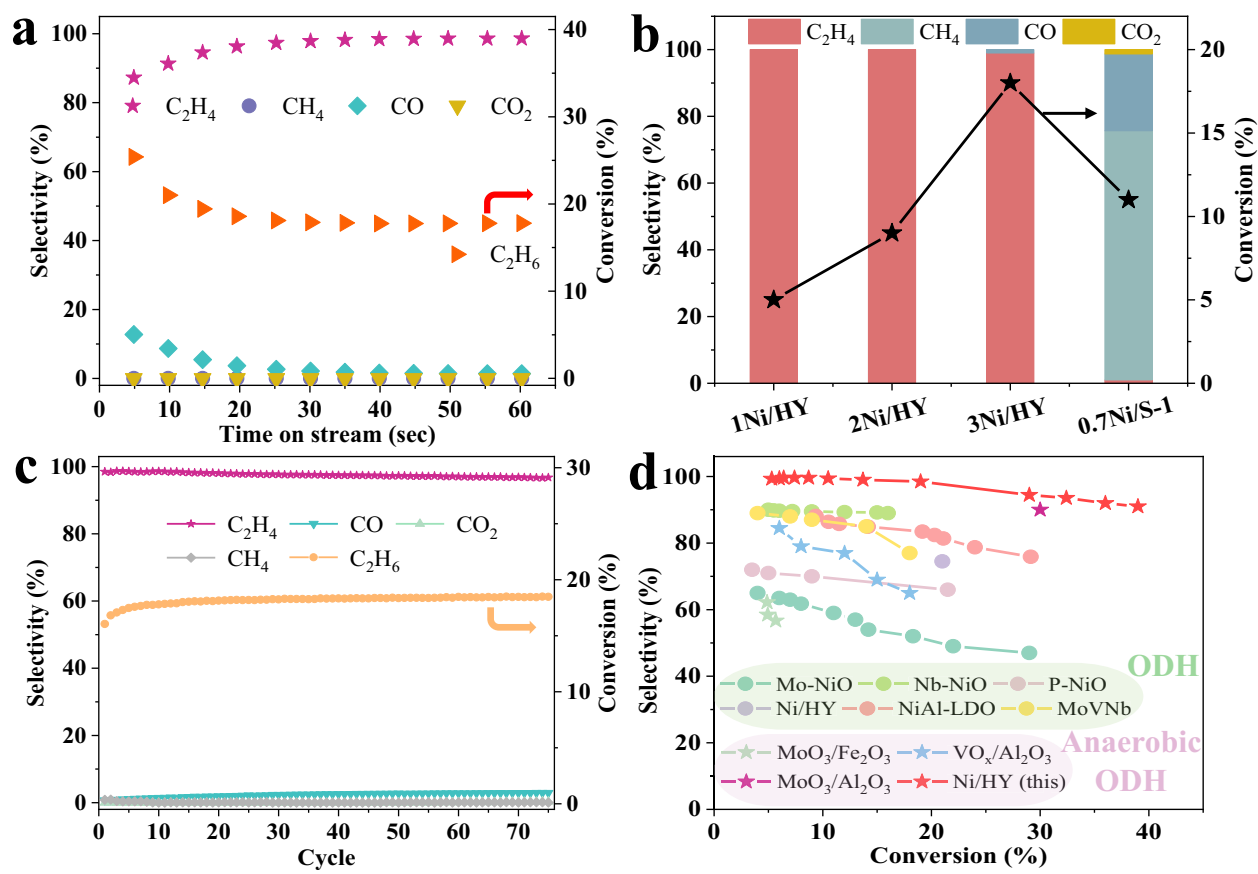

Fig. 2 Performance evaluation of $\mathbf{x N i} / \mathbf{H Y}$ for ethane ODH. a The conversion and selectivity vs. time for $3 \mathrm{Ni} / \mathrm{HY}$ sample. $\mathbf{b}$ The performance of $x \mathrm{Ni} / \mathrm{HY}$

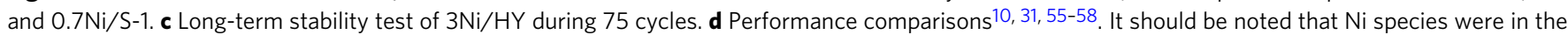
form of metallic $\mathrm{Ni}$ in $\mathrm{Ni} / \mathrm{HY}$ of ref. 47 , which was distinct from the dual active sites of Ni species in the present work. 


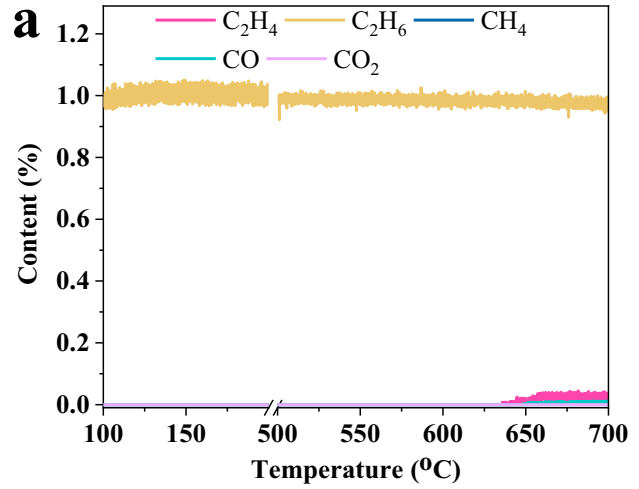

Fig. 3 Ethane TPSR. a $0.7 \mathrm{Ni@NaY} \mathrm{and} \mathrm{b} \mathrm{3Ni/HY,} \mathrm{respectively.}$

two steps usually occurred on identical active sites leading to consecutive oxidation ${ }^{10,46-48}$. Considering the critical role of oxygen reactivity for the selectivity of alkene ${ }^{2,10,49}$, we calculated the energy of oxygen vacancy formation $\left(E_{\mathrm{OV}}\right)$ of $\mathrm{NiO}$ nanoclusters confined in HY framework and bulky ones as a reference and the results indicated that $\mathrm{Ni}-\mathrm{O}$ bond energy of $\mathrm{NiO}$ nanoclusters in $\mathrm{HY}$ framework was significantly higher than those of bulky $\mathrm{NiO}$ resulted from larger $E_{\mathrm{OV}}$ (Fig. 1e, f, and Supplementary Fig. 8a, b). This could be supported by the result of $\mathrm{H}_{2}$ temperature program surface reduction $\left(\mathrm{H}_{2}-\mathrm{TPSR}\right)$ on $3 \mathrm{Ni} /$ $\mathrm{HY}$ and a reference sample of $0.7 \mathrm{Ni} /$ silicalite- $1(0.7 \mathrm{Ni} / \mathrm{S}-1)$ with $\mathrm{NiO}$ nanoclusters outside the framework of zeolite with a similar amount (Supplementary Table 1) and particle size (Supplementary Fig. 9) where reduction temperature for $\mathrm{NiO}$ nanoclusters in $3 \mathrm{Ni} / \mathrm{HY}$ was significantly higher than those in $0.7 \mathrm{Ni} / \mathrm{S}-1$ (Supplementary Fig. 10). The design of dual $\mathrm{Ni}$ active sites with decreased oxygen reactivity of $\mathrm{NiO}$ nanoclusters confined in $\mathrm{HY}$ framework would be favorable for high selectivity to alkene likely resulted from the suppression of further oxidation of alkene.

Performance of $x \mathrm{Ni} / \mathrm{HY}$ with dual Ni active sites. The performance test was carried out under oxidative dehydrogenation and regeneration cycles without co-feeding $\mathrm{O}_{2}$. Figure 2a and Supplementary Fig. 11 show the evolution of gas product composition over $x \mathrm{Ni} / \mathrm{HY}$ at $600{ }^{\circ} \mathrm{C}$. Only $\mathrm{C}_{2} \mathrm{H}_{4}$ could be observed with a negligible amount of $\mathrm{CO}_{2}$ and $\mathrm{CO}\left(\mathrm{CO}_{x}\right)$ which accounted for $\mathrm{C}_{2} \mathrm{H}_{4}$ selectivity of $99 \%$ with the highest $\mathrm{C}_{2} \mathrm{H}_{6}$ conversion of $18 \%$ for $3 \mathrm{Ni} / \mathrm{HY}$ during the overall oxidative dehydrogenation step. This indicated that our $x \mathrm{Ni} / \mathrm{HY}$ catalysts with dual $\mathrm{Ni}$ active sites successfully prevented consecutive oxidation at a relatively wide range of conversion. Comparatively, $0.7 \mathrm{Ni} / \mathrm{S}-1$ with only $\mathrm{NiO}$ nanoclusters with a similar amount (Supplementary Table 1) and particle size (Supplementary Fig. 9) without $\mathrm{Ni}^{2+}$ LAS (Supplementary Fig. 12) exhibited completely overoxidation even at a lower conversion of about $10 \%$ (Fig. $2 \mathrm{~b}$ and Supplementary Fig. 11), presenting that identical active site undertaking both dehydrogenation and oxidation in $0.7 \mathrm{Ni} / \mathrm{S}-1$ were facile to further oxidation of ethene on it. Moreover, $3 \mathrm{Ni} / \mathrm{HY}$ outperformed most conventional oxidative dehydrogenation of ethane (ODHE) catalysts (Fig. 2d), indicating that the design of dual Ni active sites in $x \mathrm{Ni} / \mathrm{HY}$ was beneficial to shun over-oxidation. It was worthwhile to note that oxygen consumption of $x \mathrm{Ni} / \mathrm{HY}$ exceeded $30 \%$ (Supplementary Table 2), suggesting that lattice oxygen of $\mathrm{NiO}$ nanoclusters participated in the reaction and exhibited inferior activity for $\mathrm{C}_{2} \mathrm{H}_{4}$ oxidation probably due to its high bond strength (Fig. If and Supplementary Fig. 10). A long-term stability test was performed over 3Ni/HY for 75 (Fig. 2c) and 108 cycles (Supplementary Fig. 13). As shown in Fig. $2 \mathrm{c}, \mathrm{C}_{2} \mathrm{H}_{6}$ conversion of about $18 \%$ and $\mathrm{C}_{2} \mathrm{H}_{4}$ selectivity of around $97 \%$ were almost

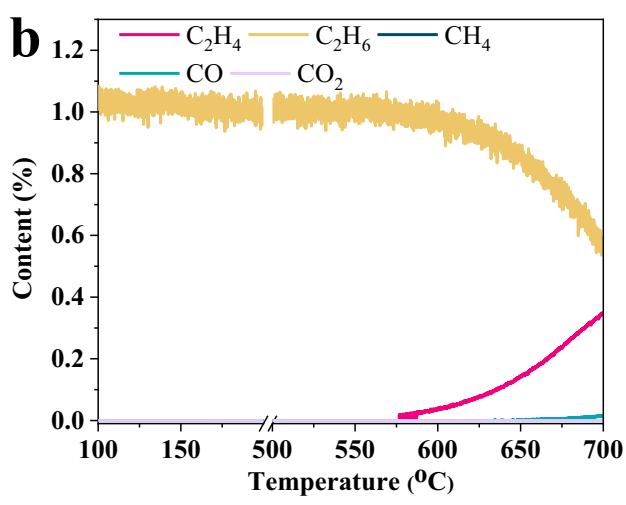

identical during 75 cycles, indicating that the stability of performance of Ni confined HY catalysts for anaerobic ODHE. The characterization results of $3 \mathrm{Ni} / \mathrm{HY}$ after reduction and long-term stability test (108 cycles) were provided in the Supplementary Figs. 14-16. It could be concluded that an identical amount of $\mathrm{Ni}^{2+}$ LAS and small $\mathrm{NiO}$ nanoclusters still residing in $\mathrm{HY}$ framework, i.e. unchanged dual $\mathrm{Ni}$ active sites, were responsible for the long-term stable performance of $3 \mathrm{Ni} / \mathrm{HY}$.

Isolating dehydrogenation and oxidation. In order to understand the superior selectivity of $x \mathrm{Ni} / \mathrm{HY}$, specific responsibility undertaken by $\mathrm{Ni}^{2+}$ LAS and $\mathrm{NiO}$ nanoclusters would be revealed. For this purpose, a reference sample of 0.7Ni@NaY was prepared (see the "Methods" section for details of its preparation) wherein the lack of BAS in $\mathrm{NaY}$ induced that $\mathrm{Ni}^{2+}$ LAS could not be generated by substituting BAS (Supplementary Fig. 17) thereby $\mathrm{Ni}$ species were present in the form of $\mathrm{NiO}$ nanoclusters confined in the framework of zeolite with a similar amount of $0.1 \mathrm{mmol} / \mathrm{g}$ and the average size of $1.2 \mathrm{~nm}$ (Supplementary Table 1 and Figs. 17, 18). Figure 3a, b shows ethane TPSR of $0.7 \mathrm{Ni@NaY} \mathrm{and}$ $3 \mathrm{Ni} / \mathrm{HY}$. For $0.7 \mathrm{Ni} @ \mathrm{NaY}$ without $\mathrm{Ni}^{2+} \mathrm{LAS}, \mathrm{C}_{2} \mathrm{H}_{6}$ consumption could hardly be observed even the temperature reached $700{ }^{\circ} \mathrm{C}$ accompanied with the formation of negligible $\mathrm{C}_{2} \mathrm{H}_{4}$ and no obvious $\mathrm{CO}_{x}$, indicating that $\mathrm{NiO}$ nanoclusters confined in $\mathrm{NaY}$ exhibited low activity for $\mathrm{ODH}$ of ethane. In comparison, $\mathrm{C}_{2} \mathrm{H}_{4}$ formed at a temperature of $580{ }^{\circ} \mathrm{C}$ without $\mathrm{CO}_{x}$ with consumption of $\mathrm{C}_{2} \mathrm{H}_{6}$ for $3 \mathrm{Ni} / \mathrm{HY}$, which strongly verified that $\mathrm{Ni}^{2+} \mathrm{LAS}$ was responsible for the catalytic dehydrogenation of $\mathrm{C}_{2} \mathrm{H}_{6}$ to $\mathrm{C}_{2} \mathrm{H}_{4}$. This could be further confirmed by inferior $\mathrm{C}_{2} \mathrm{H}_{6}$ conversion of only $0.6 \%$ for $0.7 \mathrm{Ni@NaY}$ without $\mathrm{Ni}^{2+} \mathrm{LAS}$ (Supplementary Fig. 20). The role of $\mathrm{NiO}$ nanoclusters in $x \mathrm{Ni} / \mathrm{HY}$ for this reaction was then uncovered. XPS of reduced $x \mathrm{Ni} / \mathrm{HY}$ showed that $\mathrm{Ni}^{0}$ with peak at around $852 \mathrm{eV}^{42}$ formed (Fig. 4a) and the amount of lattice oxygen in O 1s XPS decreased (Supplementary Fig. 21 and Supplementary Table 3). Moreover, the comparison of performance between $3 \mathrm{Ni} / \mathrm{HY}$-IE with only $\mathrm{Ni}^{2+}$ LAS (Supplementary Fig. 22, see the "Methods" section for details of its preparation and $\mathrm{Ni}^{2+}$ LAS amount in Supplementary Table 1) and $3 \mathrm{Ni} / \mathrm{HY}$ with dual $\mathrm{Ni}$ active sites presented that $3 \mathrm{Ni}$ / $\mathrm{HY}$ exhibited remarkably higher $\mathrm{C}_{2} \mathrm{H}_{6}$ conversion than $3 \mathrm{Ni} / \mathrm{HY}-$ IE did (Supplementary Fig. 23a) thus accounting for its larger $\mathrm{C}_{2} \mathrm{H}_{4}$ yield in spite of a slight decrease in $\mathrm{C}_{2} \mathrm{H}_{4}$ selectivity with an increase in $\mathrm{C}_{2} \mathrm{H}_{6}$ conversion (Supplementary Fig. 23b). Combining with the role of $\mathrm{Ni}^{2+}$ LAS, it could be inferred that lattice oxygen of $\mathrm{NiO}$ nanoclusters confined in the $\mathrm{HY}$ framework should be responsible for the improvement of selective conversion of ethane to ethene by oxidizing $\mathrm{H}_{2}$ rather than $\mathrm{C}_{2} \mathrm{H}_{4}$ formed from catalytic dehydrogenation of $\mathrm{C}_{2} \mathrm{H}_{6}$ on $\mathrm{Ni}^{2+} \mathrm{LAS}$. In order to confirm this, $3 \mathrm{Ni} / \mathrm{HY}$ was subjected to $\mathrm{C}_{2} \mathrm{H}_{4}$ and $\mathrm{H}_{2}$ atmosphere 

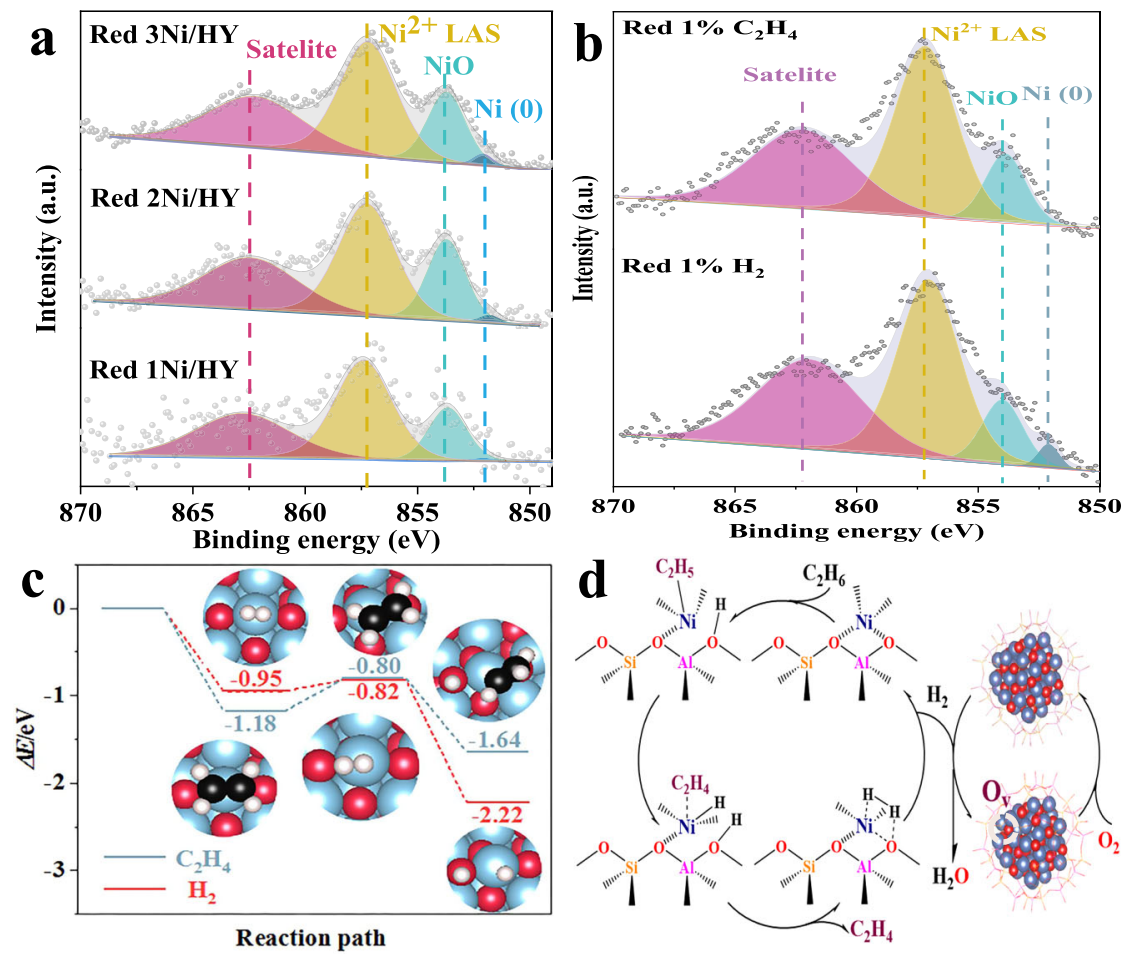

Fig. 4 Reaction mechanism. $\mathrm{Ni} 2 p^{3 / 2} \mathrm{XPS}$ spectra of a reduced $x \mathrm{Ni} / \mathrm{HY}$ samples in reaction condition, and $\mathbf{b} 1 \% \mathrm{H}_{2}$ and $1 \% \mathrm{C}_{2} \mathrm{H}_{4}$ reduced $3 \mathrm{Ni} / \mathrm{HY}$. c Potential energies profiles for $\mathrm{C}_{2} \mathrm{H}_{4}$ and $\mathrm{H}_{2}$ dissociation pathways on $1 \mathrm{~nm} \mathrm{NiO}$ cluster. Color index: $\mathrm{Ni}$, blue, $\mathrm{O}$, red, $\mathrm{C}$, black, $\mathrm{H}$, white. d Reaction mechanism proposed for anaerobic ODHE over Ni-modified $\mathrm{HY}$.

under reaction temperature to study their oxidation. It could be seen that almost no consumption of $\mathrm{C}_{2} \mathrm{H}_{4}$ as well without $\mathrm{CO}_{x}$ signals were observed while $\mathrm{H}_{2}$ signals decreased remarkably with its consumption amount of 90 times to that of $\mathrm{C}_{2} \mathrm{H}_{4}$ (Supplementary Fig. 24). Moreover, $\mathrm{Ni}^{0}$ formed after $\mathrm{H}_{2}$ reduction but did not after $\mathrm{C}_{2} \mathrm{H}_{4}$ reduction (Fig. $4 \mathrm{~b}$ ), indicating that lattice oxygen of $\mathrm{NiO}$ nanoclusters selectively oxidized $\mathrm{H}_{2}$ instead of $\mathrm{C}_{2} \mathrm{H}_{4}$ formed. DFT calculations further demonstrated that the activation barrier of $\mathrm{C}_{2} \mathrm{H}_{4}$ dissociation into $-\mathrm{C}_{2} \mathrm{H}_{3}$ and $-\mathrm{H}$ was larger than that of $\mathrm{H}_{2}$ into $-\mathrm{H}$ on $\mathrm{NiO}$ nanoclusters $(0.38$ vs. $0.13 \mathrm{eV}$ ) with lower exothermic reaction energy ( 0.46 vs. $1.27 \mathrm{eV})$ in spite of its slightly larger adsorption energy (Fig. $4 \mathrm{c}$ and Supplementary Fig. 25), implying that NiO nanoclusters confined in $\mathrm{HY}$ framework were more tendentious to oxidize $\mathrm{H}_{2}$ than $\mathrm{C}_{2} \mathrm{H}_{4}$. This is considerably persuasive from the point of thermodynamics because of the increased $\mathrm{Ni}-\mathrm{O}$ bond strength of $\mathrm{NiO}$ nanoclusters confined in $\mathrm{HY}$ framework (Fig. 1f). To verify it, we compared the performance of two double bed catalysts, namely one composed of $2.3 \mathrm{Ni} / \mathrm{HY}$-IE with only $\mathrm{Ni}^{2+}$ LAS (See the "Methods" section for details of its preparation and $\mathrm{Ni}^{2+}$ LAS amount in Supplementary Table 1) plus $0.7 \mathrm{Ni} / \mathrm{S}-1$ with only $\mathrm{NiO}$ nanoclusters outside S-1 zeolite and the other consisted of $2.3 \mathrm{Ni} /$ HY-IE plus 0.7Ni@NaY with only $\mathrm{NiO}$ nanoclusters confined inside Y zeolite. It could be seen that the double bed catalyst with $2.3 \mathrm{Ni} / \mathrm{HY}-\mathrm{IE}$ and $0.7 \mathrm{Ni} / \mathrm{S}-1$ suffered from complete overoxidation whereas that with 2.3Ni/HY-IE and 0.7Ni@NaY exhibited nearly $100 \% \mathrm{C}_{2} \mathrm{H}_{4}$ selectivity (Supplementary Figs. 26, 27 ), indicating that $\mathrm{NiO}$ nanoclusters confined in the framework with larger $\mathrm{Ni}-\mathrm{O}$ bond strength than those outsides (Fig. 1e, f) was favorable for high selectivity to ethene resulted from the suppression of further oxidation of ethene formed on the $\mathrm{Ni}^{2+}$ LAS of $2.3 \mathrm{Ni} / \mathrm{HY}$-IE. This was supported by TPSR of ethene and $\mathrm{H}_{2}$ (co-feeding) on $0.7 \mathrm{Ni} / \mathrm{S}-1$ in which the consumption of large amount of ethene and conspicuous co-production of $\mathrm{CO}_{x}$ were observed (Supplementary Fig. 28). It was noted that the increase of $\mathrm{H}_{2}$ signals should be attributed to $\mathrm{C}_{2} \mathrm{H}_{4}$ cracking accompanied with $\mathrm{CH}_{4}$ formation. As a result, the fabrication of dual $\mathrm{Ni}$ active sites with reduced oxygen activity by HY introduced in the present work isolated dehydrogenation and oxidation, which prevented ethylene from successive oxidation at a wider range of conversion in turn achieving near $100 \% \mathrm{C}_{2} \mathrm{H}_{4}$ selectivity at $18 \% \mathrm{C}_{2} \mathrm{H}_{6}$ conversion for ODHE under anaerobic mode. The potential reaction pathway was depicted in Fig. 4d. Firstly, $\mathrm{C}_{2} \mathrm{H}_{6}$ adsorbed and activated on $\mathrm{Ni}^{2+}$ LAS by breaking $\mathrm{C}$ $-\mathrm{H}$ bonding of the methyl group leading to the formation of ethylnickel $\left(\mathrm{Ni}-\mathrm{CH}_{2} \mathrm{CH}_{3}\right)$ and $\mathrm{BAS}(\mathrm{Si}-\mathrm{OH}-\mathrm{Al})$. Subsequently, $\mathrm{C}_{2} \mathrm{H}_{4}$ desorbed by the $\beta$-hydrogen elimination to form metal hydride $(\mathrm{Ni}-\mathrm{H})$ and then $\mathrm{Ni}^{2+}$ LAS active sites restored inducing the formation of hydrogen ${ }^{50}$. Finally, lattice oxygen in $\mathrm{NiO}$ nanoclusters with increased $\mathrm{Ni}-\mathrm{O}$ bond energy selectively removed hydrogen without over-oxidizing $\mathrm{C}_{2} \mathrm{H}_{4}$ (Fig. $4 \mathrm{~b}$ and Supplementary Fig. 21) bringing about $\mathrm{Ni}^{0}$ species (Fig. $4 \mathrm{a}$ ) which could be re-oxidized and regenerate to $\mathrm{NiO}$ nanoclusters by oxygen.

\section{Discussion}

In summary, this work proposed and confirmed an efficient approach to prohibit over-oxidation, thus achieving superior ethylene selectivity for oxidative dehydrogenation of ethane in a redox manner. The high selectivity was contributed by the tailoring of dual $\mathrm{Ni}$ active sites to isolate dehydrogenation and oxidation in which $\mathrm{Ni}^{2+}$ LAS undertook the catalytic dehydrogenation of ethane to ethene, while $\mathrm{NiO}$ nanoclusters embedded in $\mathrm{HY}$ framework with enhanced $\mathrm{Ni}-\mathrm{O}$ bond energy was capable to selectively transform hydrogen without overoxidizing ethylene generated. Although this work is still plain only verified by oxidative dehydrogenation of ethane and a lot of work including more sufficient experiment validation, rational catalyst design, and process optimization needs to be done, such tailoring strategy to isolate dehydrogenation and oxidation on 
dual active sites toward avoiding consecutive oxidation opens a new avenue for selectively oxidative dehydrogenation of light alkanes and could be extended to multiple oxidation reactions that tendentiously suffer from the plaguing of overoxidation.

\begin{abstract}
Methods
Preparation of Ni/HY with dual active sites. All the Ni modified HY samples (denoted as $x \mathrm{Ni} / \mathrm{HY}, x$ indicated theoretical mass fraction of $\mathrm{NiO}$ ) were synthesized by equal volume wetness impregnation method. For example, to prepare $3 \mathrm{Ni} / \mathrm{HY}$, $\mathrm{Ni}\left(\mathrm{NO}_{3}\right)_{2} \cdot 6 \mathrm{H}_{2} \mathrm{O}(0.467 \mathrm{~g})$ was dissolved in ultrapure water $(3 \mathrm{~mL})$ and then mixed with $\mathrm{HY}$ zeolite with $\mathrm{SiO}_{2} / \mathrm{Al}_{2} \mathrm{O}_{3}$ molar ratio of 5.4 (Nankai University). The resulting slurry was evenly dispersed by the aid of ultrasonic and then dried overnight at room temperature. After dried at 60 and $120^{\circ} \mathrm{C}$ for $12 \mathrm{~h}$, respectively, the samples were calcined at $600^{\circ} \mathrm{C}$ for $4 \mathrm{~h}$. Then they were ground and sieved into 40-60 mesh for reactivity evaluation.
\end{abstract}

Synthesis of silicalite-1. Silicalite-1 (S-1, a MFI-type purely siliceous zeolite) was synthesized with a molar composition of $1.0 \mathrm{SiO}_{2}: 0.2$ TPAOH:46 $\mathrm{H}_{2} \mathrm{O}$ under conventional hydrothermal conditions at $443 \mathrm{~K}$ for $72 \mathrm{~h}^{51}$. Afterwards, the assynthesized solids were centrifuged and washed several times with deionized water, then dried at $373 \mathrm{~K}$ for $12 \mathrm{~h}$ and calcined at $823 \mathrm{~K}$ for $6 \mathrm{~h}$ in air with heating rate $2^{\circ} \mathrm{C} \mathrm{min}^{-1}$ to remove the organics.

Preparation of $\mathbf{0 . 7 N i / S - 1 . ~} 0.7 \mathrm{Ni} / \mathrm{S}-1$ was also prepared by the above impregnation procedure with $\mathrm{Ni}\left(\mathrm{NO}_{3}\right)_{2} \cdot 6 \mathrm{H}_{2} \mathrm{O}$.

\section{Synthesis of 2.3Ni/HY-IE and 3Ni/HY-IE. The 2.3Ni/HY-IE and 3Ni/HY-IE} samples were synthesized by nickel exchange of the HY support using a template ion-exchange procedure ${ }^{52}$. Nickel exchange was performed at $348 \mathrm{~K}$ for $16 \mathrm{~h}$ using $200 \mathrm{ml}$ of aqueous 0.007 and $0.01 \mathrm{M} \mathrm{Ni}\left(\mathrm{NO}_{3}\right)_{2}$ solution with $4 \mathrm{~g}$ solid support, respectively. The exchanged product was collected by filtration and washed with ultrapure water. The obtained catalyst was dried at $353 \mathrm{~K}$ for $12 \mathrm{~h}$ and then calcined at $773 \mathrm{~K}$ for $4 \mathrm{~h}$

Synthesis of $\mathbf{0 . 7 N i @ N a Y . 0 . 7 N i @ N a Y ~ s a m p l e s ~ w i t h ~ c o n f i n e d ~} \mathrm{NiO}$ clusters within FAU zeolites were synthesized by the hydrothermal method in the absence of organic template agents and modified with the addition of base metal cations and protecting ligands to form confined $\mathrm{NiO}$ clusters ${ }^{53}$. Concretely, synthesis gels were prepared by first dissolving $0.65 \mathrm{~g} \mathrm{~N}$-[3-(trimethoxysilyl)propyl] ethylenediamine (TPE; 98\%, Sigma-Aldrich) and $0.2 \mathrm{~g} \mathrm{Ni}\left(\mathrm{NO}_{3}\right)_{2} \cdot 6 \mathrm{H}_{2} \mathrm{O}$ into ultrapure $\mathrm{H}_{2} \mathrm{O}(26.5 \mathrm{ml})$. $\mathrm{NaAlO}_{2}(2.34 \mathrm{~g})$ and $\mathrm{NaOH}(3.77 \mathrm{~g})$ were added sequentially while stirring $(20 \mathrm{~min})$. Colloidal silica (28.6 g; Ludox AS-30) was then added to this solution at ambient temperature and stirred for $2 \mathrm{~h}$ to prepare homogeneous synthesis gels $\left(10 \mathrm{SiO}_{2} / 1.0\right.$ $\mathrm{Al}_{2} \mathrm{O}_{3} / 4.3 \mathrm{Na}_{2} \mathrm{O} / 180 \mathrm{H}_{2} \mathrm{O} / 0.050$ metal/0.20 ligand, molar ratios). The gels were sealed within $100 \mathrm{ml}$ PTFE-lined stainless steel autoclave and heated at $393 \mathrm{~K}$ for $24 \mathrm{~h}$ without stirring to form $\mathrm{Ni} @ \mathrm{NaY}$ solids. The products were collected by filtration and washed by ultrapure water until to $\mathrm{PH}$ of $7-8$, then dried at $373 \mathrm{~K}$ for $8 \mathrm{~h}$ and heated in flowing dry air to $623 \mathrm{~K}\left(\right.$ at $\left.2{ }^{\circ} \mathrm{C} \mathrm{min}-1\right)$ and held for $3 \mathrm{~h}$. The assynthesized samples with well-defined FAU structure and about $1-2 \mathrm{~nm}$ confined $\mathrm{NiO}$ clusters without obviously $\mathrm{NiO}$ diffraction peaks and aggregation of $\mathrm{Ni}$ species outside zeolite frameworks (Supplementary Figs. 18, 19).

Characterization of materials. The crystalline structure of samples was measured by PANalytical X'Pert-Pro powder X-ray diffractometer with $\mathrm{Cu} \mathrm{Ka}$ monochromatized radiation $(\lambda=0.1541 \mathrm{~nm}, 40 \mathrm{kV}, 40 \mathrm{~mA})$. The scanned $2 \theta$ range was $10-80^{\circ}$. The $\mathrm{NiO}$ particle size and element distribution of samples before and after cycling were studied by scanning transmission electron microscopy (STEM) and energy dispersive spectroscopy (EDS), respectively, using a field-emission transmission electron microscope (JEOL JEM-2100F). The AC-HAADF-STEM analysis was performed on a JEOL JEMARM200F equipped with a CEOS probe corrector, with a guaranteed resolution of $0.08 \mathrm{~nm}$. Before microscopy examination, the sample was ultrasonically dispersed in ethanol for 15-20 min, and then a drop of the suspension was dropped on a copper TEM grid coated with a thin holey carbon film. XPS measurement of the fresh and reduced samples was performed with a VG ESCALAB210 spectrometer equipped with an $\mathrm{Al} \mathrm{Ka}(\mathrm{hm}=1486.6 \mathrm{eV}) \mathrm{X}$-ray source. The binding energies were calibrated using the $\mathrm{C} 1 s$ peak at $284.3 \mathrm{eV}$ as a reference. The Brønsted and Lewis acid sites (BAS and LAS) of samples were quantified by pyridine adsorption IR measurement. The content of BAS and LAS were obtained using molar extinction coefficients ${ }^{54}$. Actual $\mathrm{NiO}$ loadings were measured by inductively coupled plasma-optical emission spectrometry (ICP-OES) on an IRIS Intrepid II XSP instrument (Thermo Electron Corporation). The $d-d$ transition of $x \mathrm{NiO} / \mathrm{HY}(x=1-3 \%)$ and bulky $\mathrm{NiO}$ were obtained by Ultraviolet-visible (UV-vis) absorption spectroscopy on a PerkinElmer Lambda 950 spectrometer. In situ IR spectra of dehydrated $\mathrm{xNiO} / \mathrm{HY}(x=0,1,3,6)$ were analyzed by a Fourier transform infrared (FTIR) analyzer (Bruker, TENSOR27) at a transmission mode, equipped with a liquid $\mathrm{N}_{2}$-cooled mercury-cadmium-telluride detector. Dehydration was performed under vacuum at $773 \mathrm{~K}$ for $1 \mathrm{~h}$. After cooling to $393 \mathrm{~K}$, the $-\mathrm{OH}$ group signals of the samples were collected. The X-ray absorption fine structure (XAFS) at the K-edge of Ni was measured on beam line BL14W1 of the Shanghai Synchrotron Radiation Facility (SSRF), China. A double Si (111)-crystal monochromator was used for energy selection. The energy was calibrated by the Ni foil. The spectra were collected at room temperature under the transmission mode. The data were analyzed by the Athena software package.

TPSR experiment. Ethane TPSR was performed in a fixed bed reactor loaded with $200 \mathrm{mg}$ samples. The reaction temperature was monotonously increased to $700^{\circ} \mathrm{C}$ from $100{ }^{\circ} \mathrm{C}$ at a rate of $5^{\circ} \mathrm{C} \mathrm{min}^{-1}$ in $1 \% \mathrm{C}_{2} \mathrm{H}_{6} / \mathrm{He}(150 \mathrm{~mL} / \mathrm{min})$ and the outlet gas was detected by an on-line FTIR (Bruker, MATRIX-MG(HR)-01). $\mathrm{H}_{2}$ TPSR was performed in a fixed bed reactor loaded with $200 \mathrm{mg}$ samples. The reaction temperature was monotonously increased to $900^{\circ} \mathrm{C}$ from $100^{\circ} \mathrm{C}$ at a rate of $10^{\circ} \mathrm{C} \mathrm{min}-1$ in $10 \% \mathrm{H}_{2} / \mathrm{He}(30 \mathrm{~mL} / \mathrm{min})$ and the outlet gas was detected by an on-line quadrupole MS (IPI, Model GAM200).

$\mathbf{H}_{\mathbf{2}}$ and $\mathbf{C}_{\mathbf{2}} \mathbf{H}_{\mathbf{4}}$ co-feeding experiment. The $\mathrm{NiO}$ cluster oxidation for $\mathrm{H}_{2}$ and $\mathrm{C}_{2} \mathrm{H}_{4}$ was studied in a fixed bed reactor with $\mathrm{H}_{2}$ and $\mathrm{C}_{2} \mathrm{H}_{4}$ co-feeding. The reaction temperature increased to $600{ }^{\circ} \mathrm{C}$ keeping $20 \mathrm{~min}$ in an inert atmosphere. Then, $1 \%$ $\mathrm{H}_{2}-1 \% \mathrm{C}_{2} \mathrm{H}_{4} / \mathrm{He}(30 \mathrm{~mL} / \mathrm{min})$ was forced into a reactor and kept that until no obvious consumption of $\mathrm{H}_{2}$ and $\mathrm{C}_{2} \mathrm{H}_{4}$. The consumption of hydrogen and ethene was quantified by an on-line quadrupole MS (IPI, Model GAM200).

Reactive performance tests. Activity tests were performed in a quartz fixed-bed reactor with an inner diameter (ID) of $7.5 \mathrm{~mm}$ loaded with $1.0 \mathrm{~g}$ samples $(40-60$ mesh) under atmospheric pressure. The operation reaction temperature is typically $600^{\circ} \mathrm{C}$, monitored by using a $\mathrm{K}$-type thermocouple. The whole reaction process is divided into two steps, which include isolated reduction and oxidation step. The reduction step was performed with a space velocity of $5100 \mathrm{~h}^{-1}$ in $10 \%$ ethane balanced in helium for $30 \mathrm{~s}$. The samples were re-oxidized in the oxidation step by using $5 \%$ oxygen in helium with the flow rate of $30 \mathrm{~mL} / \mathrm{min}$ for $5 \mathrm{~min}$. In order to prevent the mixing between ethane and oxygen, the reactor is purged with helium $(150 \mathrm{~mL} / \mathrm{min})$ for $2 \mathrm{~min}$ between the reduction and re-oxidation step. Detailed methodologies for IR quantification and oxygen consumption calculations were described in supplementary Materials.

DFT calculations. All the oxygen vacancy formation energy was performed using the Vienna ab initio simulation package (VASP) with projector augmented-wave (PAW) method. For the relaxations of model structures of $\mathrm{NiO}$ clusters in vacuum and Zeolite, the exchange-correlation functional of general gradient approximation (GGA) type in the parameterization by Perdew-Burke-Ernzerhof (PBE) was adapt. The forces felt by each of the atoms were well converged below $0.02 \mathrm{eV} \cdot \AA^{-1}$, and the energy convergence was set as $10^{-5} \mathrm{eV}$. The relaxation of $\mathrm{NiO}$ clusters in a vacuum was done in a cubic cell of $30 \AA \times 30 \AA \times 30 \AA$. For all calculations, Hubbard U type correction was adopted to address the electron correlation for the $3 \mathrm{~d}$ electrons of $\mathrm{Ni}$ with an effective $U$ value of $5 \mathrm{eV}$, the cutoffs of the wave function is $500 \mathrm{eV}$, and A k-mesh with the density of one point per $\sim 0.03 \AA^{-3}$ was generated using the Monkhorst - Pack method. The climbing image nudged elastic band (CI-NEB) method was employed to locate the transition states.

\section{Data availability}

The data that support the findings of this study are available from the corresponding author upon reasonable request.

Received: 3 December 2020; Accepted: 24 August 2021; Published online: 14 September 2021

\section{References}

1. Grant, J. T., Venegas, J. M., McDermott, W. P. \& Hermans, I. Aerobic oxidations of light alkanes over solid metal oxide catalysts. Chem. Rev. 118, 2769-2815 (2018).

2. Chen, S. et al. Modulating lattice oxygen in dual-functional Mo- $-\mathrm{V}-\mathrm{O}$ mixed oxides for chemical looping oxidative dehydrogenation. J. Am. Chem. Soc. 141, 18653-18657 (2019).

3. Liu, Y. et al. Near $100 \%$ CO selectivity in nanoscaled iron-based oxygen carriers for chemical looping methane partial oxidation. Nat. Commun. 10, 5503 (2019)

4. Sushkevich, V. L., Palagin, D., Ranocchiari, M. \& van Bokhoven, J. A. Selective anaerobic oxidation of methane enables direct synthesis of methanol. Science 356, 523-527 (2017).

5. Gao, Y. F. et al. Recent advances in intensified ethylene production-a review. ACS Catal. 9, 8592-8621 (2019).

6. Melzer, D. et al. Atomic-scale determination of active facets on the MoVTeNb oxide M1 phase and their intrinsic catalytic activity for ethane oxidative dehydrogenation. Angew. Chem. Int Ed. 55, 8873-8877 (2016). 
7. Cheng, M. J. \& Goddard, W. A. In silico design of highly selective $\mathrm{Mo}-\mathrm{V}-\mathrm{Te}$ $-\mathrm{Nb}-\mathrm{O}$ mixed metal oxide catalysts for ammoxidation and oxidative dehydrogenation of propane and ethane. J. Am. Chem. Soc. 137, 13224-13227 (2015).

8. Zhu, Y. Y. et al. Formation of oxygen radical sites on MoVNbTeO $x$ by cooperative electron redistribution. J. Am. Chem. Soc. 139, 12342-12345 (2017).

9. Gärtner, C. A., van Veen, A. C. \& Lercher, J. A. Oxidative dehydrogenation of ethane on dynamically rearranging supported chloride catalysts. J. Am. Chem. Soc. 136, 12691-12701 (2014).

10. Gärtner, C. A., van Veen, A. C. \& Lercher, J. A. Oxidative dehydrogenation of ethane: common principles and mechanistic aspects. ChemCatChem $\mathbf{5}$, 3196-3217 (2013).

11. Sun, M. et al. Catalytic oxidation of light alkanes $(\mathrm{C} 1-\mathrm{C} 4)$ by heteropoly compounds. Chem. Rev. 114, 981-1019 (2014).

12. Rozanska, X., Fortrie, R. \& Sauer, J. Size-dependent catalytic activity of supported vanadium oxide species: oxidative dehydrogenation of propane. $J$. Am. Chem. Soc. 136, 7751-7761 (2014).

13. Ballarini, N., Cavani, F., Ferrari, M., Catani, R. \& Cornaro, U. Oxydehydrogenation of propane catalyzed by $\mathrm{V}-\mathrm{Si}-\mathrm{O}$ cogels: enhancement of the selectivity to propylene by operation under cyclic conditions. J. Catal. 213, 95-102 (2003).

14. Fu, T., Wang, Y. Q., Wernbacher, A., Schlögl, R. \& Trunschke, A. Single-site vanadyl species isolated within molybdenum oxide monolayers in propane oxidation. ACS Catal. 9, 4875-4886 (2019).

15. He, Y., Song, Y. J. \& Laursen, S. The origin of the special surface and catalytic chemistry of Ga-rich Ni3Ga in the direct dehydrogenation of ethane. ACS Catal. 9, 10464-10468 (2019).

16. Ivan, S.-B. et al. The effect of phosphorus on the catalytic performance of nickel oxide in ethane oxidative dehydrogenation. Catal. Sci. Technol. 6, 6953-6964 (2016).

17. Skoufa, Z., Heracleous, E. \& Lemonidou, A. A. On ethane ODH mechanism and nature of active sites over $\mathrm{NiO}$-based catalysts via isotopic labeling and methanol sorption studies. J. Catal. 322, 118-129 (2015).

18. Bortolozzi, J. P., Gutierrez, L. B. \& Ulla, M. A. Synthesis of $\mathrm{Ni} / \mathrm{Al}_{2} \mathrm{O}_{3}$ and $\mathrm{Ni}-\mathrm{Co} / \mathrm{Al}_{2} \mathrm{O}_{3}$ coatings onto AISI 314 foams and their catalytic application for the oxidative dehydrogenation of ethane. Appl Catal. A 452, 179-188 (2013).

19. Heracleous, E., Lee, A. F., Wilson, K. \& Lemonidou, A. A. Investigation of Nibased alumina-supported catalysts for the oxidative dehydrogenation of ethane to ethylene: structural characterization and reactivity studies. J. Catal. 231, 159-171 (2005)

20. Nakamura, K. I., Miyake, T., Konishi, T. \& Suzuki, T. Oxidative dehydrogenation of ethane to ethylene over $\mathrm{NiO}$ loaded on high surface area MgO. J. Mol. Catal. A 260, 144-151 (2006).

21. Aouine, M., Epicier, T. \& Millet, J.-M. M. In situ environmental STEM study of the MoVTe Oxide M1 phase catalysts for ethane oxidative dehydrogenation. ACS Catal. 6, 4775-4781 (2016).

22. Zhou, Y. L. et al. Enhanced performance of boron nitride catalysts with induction period for the oxidative dehydrogenation of ethane to ethylene. $J$. Catal. 365, 14-23 (2018)

23. Grant, J. T. et al. Selective oxidative dehydrogenation ofpropane to propene using boron nitride catalysts. Science 354, 1570-1573 (2016).

24. Solsona, B. et al. Oxidative dehydrogenation of ethane over Ni-W-O mixed metal oxide catalysts. J. Catal. 280, 28-39 (2011).

25. Heracleous, E. \& Lemonidou, A. A. Ni-Me-O mixed metal oxides for the effective oxidative dehydrogenation of ethane to ethylene-effect of promoting metal Me. J. Catal. 270, 67-75 (2010).

26. Solsona, B., Concepción, P., Hernández, S., Demicol, B. \& Nieto, J. M. L. Oxidative dehydrogenation of ethane over $\mathrm{NiO}-\mathrm{CeO}_{2}$ mixed oxides catalysts. Catal. Today 180, 51-58 (2012).

27. Zhu, H. B. et al. Metal oxides modified $\mathrm{NiO}$ catalysts for oxidative dehydrogenation of ethane to ethylene. Catal. Today 228, 58-64 (2014).

28. Heracleous, E. \& Lemonidou, A. Ni-Nb-O mixed oxides as highly active and selective catalysts for ethene production via ethane oxidative dehydrogenation. Part I: Characterization and catalytic performance. J. Catal. 237, 162-174 (2006).

29. Heracleous, E. \& Lemonidou, A. A. Ni-Nb-O mixed oxides as highly active and selective catalysts for ethene production via ethane oxidative dehydrogenation. Part II: Mechanistic aspects and kinetic modeling. J. Catal. 237, 175-189 (2006).

30. Zhou, Y. L. et al. Sulfate-modified NiAl mixed oxides as effective C-H bondbreaking agents for the sole production of ethylene from ethane. ACS Catal. 10, 7619-7629 (2020).

31. Zhou, Y. L. et al. Improving the selectivity of $\mathrm{Ni}-\mathrm{Al}$ mixed oxides with isolated oxygen species for oxidative dehydrogenation of ethane with nitrous oxide. J. Catal. 377, 438-448 (2019).
32. Chung, E. Y. et al. Catalytic oxygen carriers and process systems for oxidative coupling of methane using the chemical looping technology. Ind. Eng. Chem. Res. 55, 12750-12764 (2016).

33. Neal, L. M., Yusuf, S., Sofranko, J. A. \& Li, F. Oxidative dehydrogenation of ethane: a chemical looping approach. Energy Technol. 4, 1200-1208 (2016).

34. Gao, Y. F., Haeri, F., He, F. \& Li, F. X. Alkali metal-promoted $\mathrm{La}_{x} \mathrm{Sr}_{2-x} \mathrm{FeO}_{4-\delta}$ redox catalysts for chemical looping oxidative dehydrogenation of ethane. ACS Catal. 8, 1757-1766 (2018).

35. Zeng, L., Cheng, Z., Fan, J. A., Fan, L.-S. \& Gong, J. L. Metal oxide redox chemistry for chemical looping processes. Nat. Rev. Chem. 2, 349-364 (2018)

36. Zhu, X., Imtiaz, Q., Donat, F., Müller, C. R. \& Li, F. X. Chemical looping beyond combustion-a perspective. Energy Environ. Sci. 13, 772-804 (2020).

37. Solsona, B. et al. Selective oxidative dehydrogenation of ethane over $\mathrm{SnO}_{2}$ promoted $\mathrm{NiO}$ catalysts. J. Catal. 295, 104-114 (2012).

38. Zhu, H. B. et al. Ni-Ta-O mixed oxide catalysts for the low temperature oxidative dehydrogenation of ethane to ethylene. J. Catal. 329, 291-306 (2015).

39. Zhu, H. B. et al. $\mathrm{Ni}-\mathrm{M}-\mathrm{O}(\mathrm{M}=\mathrm{Sn}, \mathrm{Ti}, \mathrm{W})$ catalysts prepared by a dry mixing method for oxidative dehydrogenation of ethane. ACS Catal. 6, 2852-2866 (2016).

40. Popescu, I., Heracleous, E., Skoufa, Z., Lemonidou, A. \& Marcu, I.-C. Study by electrical conductivity measurements of semiconductive and redox properties of $\mathrm{M}$-doped $\mathrm{NiO}(\mathrm{M}=\mathrm{Li}, \mathrm{Mg}, \mathrm{Al}, \mathrm{Ga}, \mathrm{Ti}, \mathrm{Nb})$ catalysts for the oxidative dehydrogenation of ethane. Phys. Chem. Chem. Phys. 16, 4962-4970 (2014).

41. Chai, Y. C. et al. Acetylene-selective hydrogenation catalyzed by cationic nickel confined in zeolite. J. Am. Chem. Soc. 141, 9920-9927 (2019).

42. Crist, B. V. Handbook of Monochromatic XPS Spectra (Wiley, 2011).

43. Xu, J., Wang, Q. \& Deng, F. Metal active sites and their catalytic functions in zeolites: insights from solid-state NMR spectroscopy. Acc. Chem. Res. 52, 2179-2189 (2019).

44. Kolyagin, Y. G. et al. Initial stages of propane activation over Zn/MFI catalyst studied by in situ NMR and IR spectroscopic techniques. J. Catal. 238, 122-133 (2006).

45. Kazansky, V. B. \& Pidko, E. A. Intensities of IR stretching bands as a criterion of polarization and initial chemical activation of adsorbed molecules in acid catalysis. ethane adsorption and dehydrogenation by zinc ions in ZnZSM-5 zeolite. J. Phys. Chem. B 109, 2103-2108 (2005).

46. Sanchis, R. et al. NiO diluted in high surface area $\mathrm{TiO}_{2}$ as an efficient catalyst for the oxidative dehydrogenation of ethane. Appl Catal. A 536, 18-26 (2017).

47. Lin, X., Hoel, C. A., Sachtler, W. M. H., Poeppelmeier, K. R. \& Weitz, E. Oxidative dehydrogenation (ODH) of ethane with $\mathrm{O}_{2}$ as oxidant on selected transition metal-loaded zeolites. J. Catal. 265, 54-62 (2009).

48. Zhang, X., Liu, J., Jing, Y. \& Xie, Y. Support effects on the catalytic behavior of $\mathrm{NiO} / \mathrm{Al}_{2} \mathrm{O}_{3}$ for oxidative dehydrogenation of ethane to ethylene. Appl Catal. A 240, 143-150 (2003).

49. Kang, Y. et al. Improving syngas selectivity of $\mathrm{Fe}_{2} \mathrm{O}_{3} / \mathrm{Al}_{2} \mathrm{O}_{3}$ with yttrium modification in chemical looping methane conversion. ACS Catal. 9, 8373-8382 (2019)

50. Liu, J. et al. Highly-dispersed zinc species on zeolites for the continuous and selective dehydrogenation of ethane with $\mathrm{CO}_{2}$ as a Soft Oxidant. ACS Catal. 11, 2819-2830 (2021).

51. Wang, C., Zheng, M., Li, X., Li, X. \& Zhang, T. Catalytic conversion of ethanol into butadiene over high performance LiZnHf-MFI zeolite nanosheets. Green. Chem. 21, 1006-1010 (2019).

52. Joshi, R., Zhang, G., Miller, J. T. \& Gounder, R. Evidence for the coordination-insertion mechanism of ethene dimerization at nickel cations exchanged onto beta molecular sieves. ACS Catal. 8, 11407-11422 (2018).

53. Otto, T., Zones, S. I. \& Iglesia, E. Synthetic strategies for the encapsulation of nanoparticles of $\mathrm{Ni}, \mathrm{Co}$, and $\mathrm{Fe}$ oxides within crystalline microporous aluminosilicates. Microporous Mesoporous Mater. 270, 10-23 (2018).

54. Emieis, C. A. Determination of integrated molar extinction coefficients for infrared absorption bands of pyridine adsorbed on solid acid catalysts. J. Catal. 141, 347-354 (1993).

55. Elbadawi, A. H., Ba-Shammakh, M. S., Al-Ghamdi, S., Razzak, S. A. \& Hossain, M. M. Reduction kinetics and catalytic activity of $\mathrm{VO}_{x} / \gamma-\mathrm{Al}_{2} \mathrm{O}_{3}-\mathrm{ZrO}_{2}$ for gas phase oxygen free ODH of ethane. Chem. Eng. J. 284, 448-457 (2016).

56. Botella, P., Nieto, J. M. L., Dejoz, A., Vazquez, M. I. \& Martinez-Arias, A. Mo $-\mathrm{V}-\mathrm{Nb}$ mixed oxides as catalysts in the selective oxidation of ethane. Catal. Today 78, 507-512 (2003).

57. Usachev, N. Y. et al. Oxidative conversion of ethane involving lattice oxygen of molybdenum systems modified with aluminum, gallium, or yttrium oxide. Pet. Chem. 56, 841-845 (2017).

58. Novotný, P., Yusuf, S., Li, F. \& Lamb, H. H. Oxidative dehydrogenation of ethane using $\mathrm{MoO}_{3} / \mathrm{Fe}_{2} \mathrm{O}_{3}$ catalysts in a cyclic redox mode. Catal. Today 317, 50-55 (2018). 


\section{Acknowledgements}

We are grateful for the financial support provided by the National Natural Science Foundation of China (NSFC) grants (22178337, and 21706254), National Key R\&D Program of China (2016YFA0202-801), and Dalian Institute of Chemical Physics, CAS (DICP I201916). We thank X.D. and H.W. at the Dalian Institute of Chemical Physics (DICP) for their helps to set up performance evaluation apparatus.

\section{Author contributions}

C.W. performed the catalyst preparation, characterizations, and catalytic tests. B.Y. and Q.G. did the AC-TEM characterization. Y.H. carried out the DFT simulations and analysis. Y.S. and X.P. conducted the STEM examination. Y.K., C.H., and L.L. helped with the catalyst characterizations and the data analysis. H.L. and X.L. conducted the XANES examination and analysis. M.T. and X.W. conceived the idea, designed the study, analyzed the data, and co-wrote the paper. All the authors discussed the results and commented on the paper.

\section{Competing interests}

The authors declare no competing interests.

\section{Additional information}

Supplementary information The online version contains supplementary material available at https://doi.org/10.1038/s41467-021-25782-2.
Correspondence and requests for materials should be addressed to Ming Tian or Xiaodong Wang.

Peer review information Nature Communications thanks the anonymous reviewers for their contributions to the peer review of this work.

Reprints and permission information is available at http://www.nature.com/reprints

Publisher's note Springer Nature remains neutral with regard to jurisdictional claims in published maps and institutional affiliations.

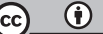

Open Access This article is licensed under a Creative Commons Attribution 4.0 International License, which permits use, sharing, adaptation, distribution and reproduction in any medium or format, as long as you give appropriate credit to the original author(s) and the source, provide a link to the Creative Commons license, and indicate if changes were made. The images or other third party material in this article are included in the article's Creative Commons license, unless indicated otherwise in a credit line to the material. If material is not included in the article's Creative Commons license and your intended use is not permitted by statutory regulation or exceeds the permitted use, you will need to obtain permission directly from the copyright holder. To view a copy of this license, visit http://creativecommons.org/licenses/by/4.0/.

(C) The Author(s) 2021 